\title{
Castelo-Branco, Salwa (dir.) (2010), Enciclopédia da música em Portugal no século XX
}

Paula Abreu

\section{OpenEdition}

\section{Journals}

Edição electrónica

URL: http://journals.openedition.org/rccs/5179

DOI: $10.4000 /$ rccs.5179

ISSN: 2182-7435

\section{Editora}

Centro de Estudos Sociais da Universidade de Coimbra

Edição impressa

Data de publição: 1 dezembro 2012

Paginação: 211-214

ISSN: 0254-1106

\section{Refêrencia eletrónica}

Paula Abreu, « Castelo-Branco, Salwa (dir.) (2010), Enciclopédia da música em Portugal no século xx », Revista Crítica de Ciências Sociais [Online], 99 | 2012, posto online no dia 04 setembro 2013, consultado o 22 setembro 2020. URL : http://journals.openedition.org/rccs/5179 ; DOI : https://doi.org/10.4000/ rccs. 5179 


\section{Recensões}

\section{Gerald Raunig, Gene Ray e Ulf Wuggenig (orgs.) (2011), Critique of Creativity: Precarity, Subjectivity and Resistance in the Creative Industries. London: MayFly, 216 pp.}

$\mathrm{O}$ debate sobre as indústrias culturais e criativas ganhou visibilidade nos últimos anos, ultrapassando o contexto académico e invadindo o espaço público, através dos média e dos agentes políticos. No contexto europeu a "agenda da criatividade" constitui hoje uma das principais tendências estruturadoras dos discursos e das práticas políticas.

A obra Critique of Creativity, recentemente publicada, insere-se nesta discussão. Este livro pretende contribuir para a análise do recente bype em torno da criatividade e das indústrias criativas, procurando equacionar alguns dos impactos ao nível das transformações no mercado laboral, nas políticas públicas, na esfera artística e cultural, entre outras. O livro divide-se em quatro partes - "Criatividade", "Precariedade", "Indústrias Criativas", "Indústrias Culturais" - que correspondem a diferentes entradas para uma abordagem crítica à temática das indústrias culturais e criativas e aos múltiplos efeitos gerados pela recente ideologia da "criatividade" e do "empreendedorismo criativo". Os 14 artigos, precedidos por uma introdução e enquadramento geral, resultam de uma seleção de comunicações apresentadas, em 2006, nas conferências "Critique of Creative Industries" e "Creating Effects: On the Ideology and Effectivity of Creativity and its Institutions". A diversidade disciplinar dos autores reflete-se num esforço dos editores em fazer dialogar abordagens distintas: umas vincadamente teóricas; outras inspiradas na análise de casos empíricos; outras ainda fundamentadas na análise de objetos artísticos.
O processo de reestruturação do modelo capitalista que, a partir de meados dos anos 70 , se generalizou por todo o mundo assume-se, neste contexto, como um elemento de análise fundamental, presente na generalidade das perspetivas apresentadas. Esta opção corresponde, por um lado, à necessidade de enquadrar as especificidades atuais do mercado de trabalho artísticos e criativo no seio das recentes transformações que caracterizam a nova economia capitalista, nomeadamente, no que diz respeito às profundas alterações operadas nos modelos de produção e de gestão do mercado de trabalho. Permite, por outro lado, desenvolver uma análise crítica dos discursos em torno das novas modalidades de emprego e trabalho, que se inspiram na figura do "artista" enquanto modelo a seguir.

As duas primeiras secções centram-se no modo como o termo "criatividade" penetrou nas retóricas da política, da gestão e da economia contemporâneas. Um dos aspetos abordados (sobretudo com Stefan Nowotny, Maurizio Lazzarato e de Paolo Virno) prende-se com o processo através do qual o trabalho artístico se tornou "exemplar" para o modelo de capitalismo atual, que celebra a sua "flexibilidade", "criatividade", "autonomia", "mobilidade" e "empreendedorismo", fazendo-a corresponder a uma certa ideia de liberdade individual.

O modo como os agentes e instituições culturais foram incorporando, ou não, estes novos discursos em torno da "criatividade" é outro aspeto abordado. 
Este é um processo evidentemente repleto de tensões e contradições pois a nova retórica da criatividade parece não conseguir dar uma resposta à precarização crescente e generalizada das condições de trabalho. A leitura cruzada de alguns dos artigos revela-se útil, ao evidenciar que a emergência de novos e diversificados espaços e movimentos que procuram resistir ao capitalismo neoliberal é simultaneamente acompanhada pela forte tendência para um certo conformismo face à situação atual, por vezes, reforçada através do contributo de artistas, intelectuais e outros agentes culturais que ativamente "alimentam" muitos dos discursos e práticas em torno da "criatividade".

A terceira secção integra um conjunto de case studies sobre o modo como têm sido delineadas e aplicadas na Europa diferentes estratégias de desenvolvimento de indústrias culturais e criativas. Os artigos abordam casos com níveis de intervenção e contextos históricos distintos, permitindo ao leitor estabelecer algumas comparações pertinentes.

Num plano macro, Raimund Minichbauer propõe uma análise crítica da crescente presença do discurso em torno da "criatividade", "indústrias criativas" e "economia criativa" nas políticas culturais da União Europeia, sobretudo com a "Estratégia de Lisboa" (2000) e a aposta numa "economia da informação e do conhecimento". Como demonstra, este discurso reflete um agudizar de uma tendência para a economização da política cultural comunitária, que se repercute numa alteração das prioridades políticas para o setor.

As análises de Angela McRobbie e de Monika Mokre centram-se num nível intermédio - i.e. abordam as implicações dos discursos, estratégias e instrumentos de política concretos ao nível das cidades e dos países. Estas investigadoras propõem-nos, respetivamente, a análise dos casos do Reino Unido/Londres (uma reflexão sistemática e muito bem fundamentada do que McRobbie classifica como as três "vagas" sucessivas de microempreendedores criativos britânicos, desde os anos 90) e da Áustria/Viena (centrada, em particular, na análise do malsucedido projeto "Quartier 21").

Num plano micro, Marion von Osten centra-se no setor do design e multimédia, em Zurique, apresentando uma reflexão sobre os impactos das modalidades de emprego e de auto-organização específicas neste contexto. Esta investigação revela algumas das tensões e das táticas de resistência quotidianas levadas a cabo por estes agentes face ao que interpretam como uma economização da cultura.

$\mathrm{Na}$ quarta e última secção revisitam-se os célebres argumentos de Max Horkheimer e Teodoro W. Adorno sobre a "indústria cultural”. Gene Ray e Esther Leslie, por um lado, desenvolvem nos seus respetivos artigos duas releituras possíveis das teses de Horkheimer e Adorno à luz do contexto presente, defendendo, em ambos os casos, que estas se mantêm genericamente ajustadas e atuais. Gerald Raunig, por seu turno, propõe uma visão mais crítica, desenvolvendo uma análise sistemática dos quatro elementos centrais que compõem o conceito de "indústria cultural" e confrontando-os com os atuais desenvolvimentos. A sua análise demonstra como os pressupostos que sustentavam a tese da manipulação e subjugação dos indivíduos ao capital através da indústria cultural se revelam desfasados da realidade do capitalismo pós-fordista contemporâneo e, em particular, das transformações ocorridas no campo da cultura. Torna-se, assim, necessário encontrar novos referenciais teóricos, convocando o autor os contributos de Deleuze e Guattari, Lory e Virno para este debate.

Para concluir, importa realçar a pertinência e atualidade do conjunto de ensaios 
aqui reunidos, possibilitando ao leitor uma visão crítica das indústrias criativas contemporâneas, seja como ideologia, seja enquanto relações de exploração que se concretizam na praxis quotidiana daqueles que nelas se encontram envolvidos. São ainda apontadas pistas de investigação relevantes para o desenvolvimento de algumas das linhas de problematização aqui enunciadas, nomeadamente, no que toca às práticas reais e potenciais de resistência no campo cultural, a diferentes níveis (das lutas sociais mais institucionalizadas e organizadas, às microtáticas quotidianas de resistência). Saliente-se ainda o contributo desta obra para enriquecer o debate sobre as indústrias culturais e criativas, propondo um cruzamento de perspetivas que favorecem um enriquecimento desta discussão e também que esta extravase as esferas política, técnica e científica, alargando-se a outros contextos. Não podemos, contudo, concluir sem referir que, por vezes, a perspetiva patente em Critique of Creativity evidencia um "tom" excessivamente crítico das indústrias criativas, que parece ser incapaz de matizar a análise e integrar as aprendizagens, oportunidades e transformações positivas que, para além do bype, algumas destas dinâmicas e transformações também originam ou poderão potencialmente vir a originar.

Pedro Quintela

\section{Whybrow, Nicolas (2011), Art and the City. London, New York: I. B. Tauris, $198 \mathrm{pp}$.}

Zygmunt Bauman escrevia em 1991 que, na pós-modernidade, o novo flâneur 'viajante-jogador' prefere a irremediável redundância ao jogo da sobrevivência, isto é, o divertimento consciente de si como jogo 'maduro' e 'puro' que olha o mundo como teatro e a vida como jogo. Em Não-lugares: introdução a uma antropologia da sobremodernidade (2005), Augé sublinha a necessidade de conferir um sentido, "pela intensidade da experiência" (a performance), ao presente e aos "não-lugares" do mundo, como contrapartida pela sobreposição e excesso dos acontecimentos, pela superabundância espacial e individualização das referências, modalidades que caracterizam os novos tempos "sobremodernos". Em Art and the City, Nicolas Whybrow, especialista em Estudos do Teatro e da Performance, Professor na Universidade de Warwick no Reino Unido, associa à recente proliferação e 'translocalização' dos sítios e lugares de arte para fora dos museus, a 'recolocação' do "corpo relacional" (8) como centro e espaço de produção, circulação e receção dos discursos culturais e socioeconómicos urbanos. Salienta, neste sentido, o papel de resistência reservado especificamente ao corpo lúdico e performativo no espaço da revolução eletrónica e fibro-ótica e das transformações em curso na cidade desde os meados do século anterior, de que Virilio é o principal arauto e com cujas teorias este texto dialoga.

Na sua mais recente monografia, o também editor do recente e panorâmico estudo sobre performance e práticas urbanas de arte no século Xx, Performance and the Contemporary City: An Interdisciplinay Reader (2010), começa por relacionar a "experiência momentânea" dos incidentes urbanos de Lefebvre, que este identifica também na arte, com as seguintes noções de 'jogo' e 'trabalho': "Por um lado, a cidade é em si própria, um 'trabalho' (de arte), ou 'obra', a qual invoca o direito cidadão à participação (ou apropriação 
pública) como arte. Por outro, a arte [...] pode 'utilmente' funcionar na cidade como meio para trazer ao jogo aquilo que está a ter lugar" (18). Na abertura da reflexão (capítulo 1), o autor relaciona estes conceitos com os de cidade-sítio como mediação cultural na relação com a viragem urbano-performativa, na qual o espectador emerge como participante engajado - na linha das teses de Kwon (2009) - portanto como interveniente na produção da cultura urbana globalizada enquanto evento/arte relacional que reproduz uma "discursividade para sempre inacabada" (Bourriaud, 2002) de identidades, estados e deslocamentos em permanente transição. Ainda na justificação teórica (capítulo 2), e na continuidade da análise da arte como "trabalho/jogo", o autor descreve a "experiência situada" como "prática crítica" (36) do interlocutor urbano. Identifica neste sentido a "escrita relacional" como escrita performativa, assumindo-se como escritor no seu papel performativo. A novidade propriamente dita deste trabalho surge na segunda parte, isto é, na ilustração daqueles pressupostos teóricos com o relato descritivo dos "encontros situados" (40) e da "experiência afetiva" (43) de lugares/instalações de arte em três cidades distintas, Londres, Berlim e Viena. Os deslocamentos e configurações experimentais da invenção artística no espaço urbano são aqui analisados no seu potencial para, ora reorganizar o visível e o sensível, ora recompor os espaços políticos, para usar a terminologia de Rancière que o autor, aliás, quase não cita.

A segunda secção do livro divide-se por três categorias de eventos, correspondentes aos capítulos 3, 4 e 5 respetivamente: "walking art", "playing fields" e "performing memory", todas implicando a participação contingente do espectador, pelo movimento, pelo jogo e pela ativação da memória. No respeitante à primeira categoria, referem-se os trabalhos artísticos de Wentworth (projeto das visitas-guiadas alternativas por Londres e o Skulptur Projekte), Alÿs (Seven Walks, The Modern Procession), Wallinger (Zone e State Britain), Metzger (Aequivalenz-Shattered Stones) ou Althamer (Path). A partir da análise destas propostas, reconhece-se a "heterodoxa interdependência das coisas" na cidade (Wentworth) pela constatação da presença e importância da adversidade e do conflito como dimensões constitutivas das democracias urbanas ("paradoxo democrático” de Mouffe, 2000); analisa-se as táticas dissolutivas do movimento, a transformação do vazio pelo happening que exige a criação de um sentido pelo discurso social, ao mesmo tempo que se alerta para as "discrepâncias do acesso e do privilégio” (73) (Alÿs); como estádios temporários, as instalações de Wallinger, Metzger e Althamer são descritas enquanto experiências espontâneas e imprevisíveis que potenciam as incursões indefinidas dos sentidos e das ligações entre espaço e espectador implicado nos ciclos sociopolíticos e históricos da cidade. No capítulo seguinte, a cultura urbana do flash mob e do mobile clubbing (analisadas na ótica de Dyer e de McGonigal), do skateboarding, do graffiti (onde se destaca o misterioso trabalho de Bansky), do parkour ou de outros projetos mais abrangentes - como o Fourth Plinth, com especial relevo para a escultura Alison Lapper Pregnant (que faz a capa do livro), de Marc Quinn é analisada como processo de reconhecimento, posicionamento e contestação das contradições agonísticas do espaço citadino. Aqui a interação cidade-arte-corpo é identificada na improvisação de jogos e ritmos, formas de divertimento e risco de potencial radical, com vista ao aprofundamento de uma consciência mais política e ética. Finalmente, no último capítulo do livro, o pretexto para o diálogo interpelativo 
e interrogativo são duas das mais controversas instalações memorialísticas da cultura europeia, a saber, o Denkmal für die ermordeten Juden Europas (Memorial aos Judeus Assassinados na Europa), de Eisenman, em Berlim, e o Memorial to the 65,000 Murdered Austrian Jews de Rachel Whiteread, em Viena. Nestes monumentos que fazem emergir as narrativas agonísticas potenciadas pelo jogo aberto da construção, o autor observa detalhadamente a arquitetura dos espaços, do monumento e envolventes, indicativa do fluxo e refluxo do debate sobre a memória problemática do Holocausto naquelas cidades. Tratando-se de formas de arte que se engajam no contexto e conflitos específicos dos lugares, Whybrow refere que a "recodificação retroativa” (Hall Foster) assegura a continuidade do debate sobre a presença de espectros de um passado quase impenetrável (à semelhança da "biblioteca fechada” de Whiteread). As respostas físicas e comportamentais concretas inerentes à organização do espaço são, segundo o autor, propiciadoras, em ambos os casos, de um importante diálogo cidadão sobre os "segredos horríveis" (Freud) da psique coletiva.

Em suma, trata-se de um trabalho interessante que alia, a uma escrita simultaneamente clara e de pendor ensaístico, o exercício crítico de uma análise que, baseando-se em pressupostos teóricos e resistindo a interpretações fechadas, é aprofundada pela descrição detalhada e interpelativa de estudos de caso e narrativas empíricas que observam a metodologia de investigação histórica e sociológica não-ortodoxa conforme proposta por Benjamin no "Projeto das Arcadas", na linha de uma sociologia histórica da flânerie. Problematizando os desafios da arte politicamente engajada, salienta-se o modo como as performances artísticas in situ podem (re)negociar efetivamente com o constrangimento e restringimento das atuais políticas públicas de planeamento e vigilância urbana, analisando-se especificamente a articulação destas práticas emergentes com a discussão dos modos e perfis ideológicos de uma "criminologia da intolerância" (120).

Duas fragilidades apontam-se por fim, a esta obra: a ausência de uma conclusão final que sistematize as densas questões e reflexões levantadas ao longo de grande parte do livro, a extensa segunda secção; a análise propriamente dita não beneficia de um pendor comparativo com outras realidades que não a ocidental por se cingir o estudo de caso a monumentos, eventos e instalações de cidades europeias. Esse risco é no entanto desde logo assumido pelo autor que nega a intenção de propor qualquer argumento linear ou conclusão do livro como um todo. Abrindo-se desta feita a novas discussões e debates, este estudo constitui um ponto de partida útil para estudos semelhantes.

Sandra Guerreiro Dias

\section{Lorentzen, Anne; Van Heur, Bas (orgs.) (2012), Cultural Political Economy of Small Cities. London e New York: Routledge, 216 pp.}

O livro Cultural Political Economy of Small Cities é uma coletânea de textos sobre as estratégias de desenvolvimento urbano assentes na cultura e nas artes. Tais estratégias são abordadas tendo em conta os seus conteúdos e efeitos, os contextos particulares (em termos geográficos e históricos) onde são aplicadas e os tipos de reações e debates que suscitam. Esta obra centra-se no universo das pequenas cidades entendidas 
geralmente numa lógica contextual e relacional no conjunto das hierarquias urbanas (em alguns textos, surgem mesmo estudos de cidades consideradas de média dimensão). Na grande maioria dos textos são apresentados estudos de caso que envolveram a realização de entrevistas e o recurso a dados estatísticos e à análise documental.

Como é assinalado pelos editores desta obra na secção introdutória (capítulo 1) de que são autores, segue-se uma abordagem situada no domínio teórico da economia política cultural, ou seja, uma perspetiva centrada na materialidade económica e numa consideração dos processos históricos e da ação estatal, por contraponto com as visões da economia política convencional. Assume-se uma distância face a "formas 'soft' de economia cultural" (p. 4) e uma proximidade aos pressupostos e implicações do Lancaster School CPE Project. Os editores do livro referem que os textos aí incluídos consistem em reflexões dirigidas para três dos eixos constituintes da abordagem teórica assinalada: "imaginários económicos; estratégias; e o papel da variação, seleção e retenção" (p. 4) de componentes discursivas dos factos sociais.

No segundo capítulo, Bas van Heur prolonga a reflexão teórica enunciada anteriormente, fazendo uma leitura crítica quer da abordagem da economia cultural (ou da economia cognitivo-cultural) de Allen J. Scott, quer da perspetiva de Richard Florida quanto à classe criativa. Discute também o conceito de imaginários económicos e elabora uma proposta analítica da socioespacialidade inspirada nas ideias de $\mathrm{N}$. Brenner assente em quatro dimensões distintas: lugar, território, escala e redes. No terceiro capítulo, Høgni Kalsø Hansen e Lars Winther mostram como o modelo de crescimento económico assente nos encantos e prazeres que as cidades proporcionariam (através, por exemplo, da sua tolerância, beleza, design urbano, cultura, espírito acolhedor) não se constitui como universal, resultando em vários impasses e contradições enquanto solução de planeamento, à semelhança do anterior paradigma do cluster. É assinalado que a opção pelo investimento num ambiente citadino renovado "não é necessariamente a cura rápida para economias regionais débeis" (p. 37).

No quarto capítulo, Chris Brennan-Horley mostra-nos de que modo se pode construir uma metodologia assente na cartografia para dar conta de dinâmicas criativas urbanas que ficam por captar usando os métodos mais convencionais. $\mathrm{O}$ autor conjugou os mapas mentais desenhados pelos moradores da cidade australiana de Darwin por si entrevistados com as técnicas de Geographic Information System. O objetivo era o de construir mapas que permitissem visualizar as geografias da criatividade de acordo com três dimensões: epicentros criativos (zonas onde os entrevistados consideravam que a atividade criativa era mais evidente); espaços de inspiração (sítios da cidade que serviam de inspiração para o trabalho criativo dos inquiridos) e "os locais de trabalho [...] da cidade criativa" segundo os referidos habitantes (p. 46).

No quinto capítulo, Anne Lorentzen discute o caso da cidade dinamarquesa de Frederikshavn, através de uma análise da produção e consumo de experiências assente nos seguintes eixos: palcos e lugares, atividades periódicas, eventos únicos, serviços e bens, símbolos, atores e instituições. O texto mostra de que modo as estratégias de crescimento económico deste tipo necessitam de reunir condições estruturais que não estão acessíveis a todas as pequenas cidades, embora a autora chame a atenção para o facto de que "[a] economia da experiência tende a ser menos 
centralizada geograficamente do que a economia do conhecimento ou a economia industrial" (p. 68).

No sexto capítulo, Heather M. Hall e Betsy Donald apresentam o seu estudo centrado na cidade periférica canadiana de Greater Sudbury. As autoras mostram como nesta localidade se desenvolveu uma estratégia frutuosa assente na criatividade, chamando, no entanto, a atenção para os principais obstáculos que se colocam a este tipo de dinâmicas.

Para os sucessos alcançados terão contribuído fatores como a aposta em recursos naturais e a inovação no setor mineiro, o que conduz a uma crítica de algumas noções de economia criativa de onde estão excluídos trabalhos e atividades mais tradicionais.

No sétimo capítulo, Douglas Chalmers e Mike Danson abordam o caso de Glasgow (Escócia) no âmbito das reconfigurações a que a cultura gaélica tem estado sujeita nas últimas duas décadas - aquilo que era muitas vezes enquadrado numa lógica conservadora e virada para o passado passou a ser reinventado em termos de criatividade e inovação. Esta mudança tem contado com uma série de atores e práticas, tais como bandas rock, sessões de dança ou o novo canal BBC Alba (todos integrantes de um setor cultural e criativo específico que não se restringe aos membros da comunidade gaélica). Os autores defendem, assim, que o estudo das artes e cultura na economia pode abarcar "aspetos da diferença cultural e linguística” (p. 96).

No oitavo capítulo, Søren Smidt-Jensen analisa o caso da cidade dinamarquesa de Vejle, mostrando de que modo esta localidade foi convertida "numa 'paisagem de experiência' espetacular” (p. 113), através de uma estratégia assente na articulação entre o mundo dos negócios, da política e diversos técnicos. Foi adotada uma política arquitetónica que destacava a importância de um ambiente construído de alta qualidade. Contudo, vários fatores acabaram por inibir, limitar ou suspender muitos dos projetos concebidos, como, por exemplo, a crise financeira surgida nos últimos anos e mudanças políticas que conduziram a uma alteração na perspetiva de como apoiar zonas diferentes do município.

No nono capítulo, Alison Bain e Dylann McLean analisam o caso das cidades canadianas de Peterborough e Thunder Bay, mostrando como a aposta na criatividade e na cultura deve ter em conta as dinâmicas informais do quotidiano das cidades, nomeadamente no que diz respeito à produção e reprodução de capital social nos chamados "terceiros lugares" (cafés, bares, restaurantes, etc.), bem como em instituições culturais mais estabelecidas (universidade e galerias públicas, por exemplo). Estes espaços "tornam-se sítios ideais para a troca inter-organizacional e frequentemente intra-organizacional de informação e ideias" (p. 135). Desta forma, é possível captar uma criatividade urbana eclética baseada "em oportunidades para colaboração e experimentação interdisciplinar entre profissionais e amadores" (p. 128).

No décimo capítulo, Paul L. Knox e Heike Mayer mostram de que forma as pequenas cidades na Europa estão a constituir redes transnacionais através das quais se inserem no sistema urbano europeu. Analisam o desenvolvimento policêntrico como um dos novos imaginários económicos, diferenciando o policentrismo institucional do policentrismo reflexivo. Este último distingue-se pela existência de uma lógica bottom-up e por se referir a "redes independentes e ad hoc de pequenas cidades" (p. 148), como, por exemplo, o movimento Cittaslow. Os autores avaliam criticamente tal movimento tendo em conta o estudo de duas das cidades aí integradas: Ludlow (Inglaterra) e Hersbruck (Alemanha). 
No décimo primeiro capítulo, Nancy Duxbury analisa como a cultura se insere no planeamento urbano de um conjunto de 27 cidades canadianas classificadas de acordo com a sua dimensão (muito pequenas, pequenas, pequenas médias e pequenas grandes cidades) e com o seu estatuto estrutural (centros regionais, cidades satélite e cidades capitais). O recurso a estas tipologias permite compreender diferenças de governação da cultura, tendo em conta diversos aspetos: importância do papel da comunidade e do voluntariado, níveis de integração e complexidade das políticas locais, objetivos da aposta na criatividade, relações entre poder local e empresas privadas ou ainda o tipo de influência dos paradigmas do planeamento urbano.

No décimo segundo capítulo, Nina Gribat analisa o caso da cidade alemã de Hoyerswerda confrontada com um cenário de declínio económico e demográfico. Segue um enquadramento teórico onde se torna prioritário estudar "como a economia e a cultura são constituídas como 'governáveis'” (p. 180). A autora mostra como o futuro desta localidade se torna problemático em torno de subjetividades culturais e narrativas em conflito. Para alguns setores, o passado comunista da cidade teria criado uma cultura de passividade nos indivíduos e anulado o desenvolvimento de um espírito empreendedor; para outros, é esse mesmo passado que confere um lugar especial a Hoyerswerda garantindo-lhe um potencial para construir o seu futuro - a ideia é a de que, em face do muito que o governo socialista deixava por fazer, os indivíduos tiveram de inventar e criar em comum uma série de dinâmicas nomeadamente culturais. "Enquanto a primeira posição pode ser encontrada na maioria dos documentos oficiais da cidade e na sua prática atual de 'regeneração por demolição', a segunda pode ser encontrada num leque de projetos culturais e artísticos” (p. 187).
No último capítulo desta obra, Jennifer Mapes discute os casos de três cidades dos EUA (Ellensburg, Steamboat Springs e Silver City), analisando o modo como a aposta na economia criativa acabou por produzir aí paisagens de nostalgia (pp. 202-204) que "emergem não só a partir de esforços para preservar edifícios do passado, mas também em tentativas para recriar paisagens físicas e culturais que desapareceram” (p. 204). A estratégia de atrair visitantes e moradores para estas localidades baseou-se num conjunto de representações idealizadas sobre as pequenas cidades encaradas como lugares tranquilos, seguros, com qualidade de vida e "sentido de comunidade" (p. 203). Surgiram, contudo, dinâmicas de conflito ou tensão quando se tratava de equacionar novos projetos ou novos negócios levando a discussões "sobre o que constitui mudança 'a mais”” (p. 206). "[À] medida que os efeitos do marketing de lugar e de outras políticas emergem, residentes e líderes igualmente começam a reconhecer a ironia de promover a pequenez com vista a um crescimento maior" (p. 207).

Um dos grandes méritos deste livro consiste em tratar de temáticas da economia cultural e do desenvolvimento urbano tendo em conta o universo das pequenas cidades que é muitas vezes objeto de pouco interesse ou menos consideração no âmbito das pesquisas académicas. Amplia-se, assim, a capacidade de compreender a realidade urbana sem que esta última fique centrada excessivamente nas metrópoles e nos seus grandes eventos culturais. Disto isto, fica em aberto a necessidade de alargar o alcance das geografias dos estudos de caso, de modo a podermos conhecer melhor pequenas cidades quer de outros países desenvolvidos quer de países em desenvolvimento. A obra consegue igualmente tirar partido de muitas 
das oportunidades de leitura oferecidas pela abordagem teórica da economia política cultural, embora a influência desta perspetiva, ao longo dos diversos capítulos, não tenha sempre o mesmo peso ou natureza. $\mathrm{O}$ eixo teórico relativo aos imaginários económicos não parece estar tão dissecado quanto os referentes às estratégias e aos constrangimentos (mais estruturais ou conjunturais), o que não o impede, todavia, de se revelar como uma linha de problematização de grande valor heurístico para aprofundamento em investigações futuras.

André Brito Correia

\section{Castelo-Branco, Salwa (dir.) (2010), Enciclopédia da música em Portugal no século xx. Lisboa: Círculo de Leitores/Temas e Debates, 4 volumes.}

\begin{abstract}
A Enciclopédia da música em Portugal no século XX (EMPXX), publicada em quatro volumes, ao longo de 2010, sob a direção de Salwa Castelo-Branco, é uma obra de referência para todos os interessados (investigadores, profissionais, jornalistas ou amadores) no conhecimento dos universos da música, em Portugal, durante o século XX. A sua importância é tanto maior quanto o seu objeto de referência e análise - os universos da música no nosso país se encontra, ainda, muito pouco descrito, analisado, discutido e teorizado.
\end{abstract}

Desse ponto de vista, é fundamental reconhecer o papel que a responsável pela direção desta obra, Salwa Castelo-Branco, e o Instituto de Etnomusicologia - Centro de Estudos em Música e Dança (INET-MD), da Faculdade de Ciências Sociais e Humana da Universidade Nova de Lisboa, por ela mesmo dirigido, têm desempenhado na exploração deste imenso campo. O seu contributo tem sido fundamental a dois níveis distintos, mas complementares. $\mathrm{O}$ primeiro diz respeito ao desenvolvimento, no nosso país, de uma inovadora abordagem multidisciplinar sobre os diversos universos musicais, enfrentando as dificuldades de diálogo disciplinar, nomeadamente entre ciências musicais e ciências sociais e humanas, que o clássico enfoque da musicologia e da história da música nunca facilitaram.
O segundo nível refere-se à forma como têm vindo a rasgar o domínio empírico dos estudos sobre a música, abrindo-o não apenas à pluralidade das expressões musicais contemporânea, como também aos mundos culturais e sociais em que estas emergem. Esta abertura traduz uma prática de investigação comprometida com a desconstrução do persistente paradigma analítico da cultura, transversal às várias disciplinas, que conceptualiza uma visão tripartida dos campos artísticos e culturais, distinguindo formas de alta cultura, de cultura média e de cultura popular (vertido, no caso da música, na distinção entre musica erudita, musica popular urbana e música tradicional).

A EMPxx é o resultado exemplar desta orientação científica, cultivada por Salwa Castelo-Branco e pela equipa de investigação do INET-MD e plasmada no texto de introdução à obra, que surge no primeiro volume:

Na sua organização global, a obra assenta na visão de um universo musical plural e dinâmico, compreendendo campos sociais distintos, construídos em torno de géneros e práticas musicais, interligadas e com fronteiras fluídas, referidos na obra como domínios. [...] A partir desta visão, não perspectivamos os domínios como categorias estáticas e unificadas, 
que se caracterizam por constelações de elementos estilísticos presumivelmente "autênticos", rígidos e perenes, mas sim como modelos subjectivos e fluidos que estão em constante mudança. [...] A obra privilegia uma abordagem multidisciplinar, integrando perspectivas teóricas e metodológicas actuais da Etnomusicologia, da Musicologia Histórica, dos Estudos da Música Popular, da Antropologia, da Sociologia e da História. Duas perspectivas complementares norteiam a abordagem dos processos sociais examinados: a música enquanto reflexo dos contextos cultural, social e político que a configuram; e a música como meio eficaz para construir processos sociais e para representar ideologias. (Castelo-Branco, 2010: V-VI)

Testemunham isso mesmo, tanto a pluralidade dos autores (cerca de uma centena e meia), com formações heterogéneas em múltiplas áreas disciplinares e/ou com práticas profissionais, chamados a colaborar na elaboração dos verbetes que constituem a EMPxx, como também o vasto conjunto de entradas subjacentes à formulação dos mesmos verbetes, cujos difíceis critérios de seleção se encontram explicitados no texto de introdução da obra: procura de equilíbrio entre diferentes domínios musicais; representação dos vários períodos históricos do século XX; apresentação dos percursos e impactos dos vários agentes da produção musical e das instituições relevantes; inclusão dos processos sociais, culturais e políticos que marcaram os universos da cultura expressiva do país nesse século; consideração das articulações entre estes processos nas escalas local, nacional, transnacional e global (Castelo-Branco, 2010: IX).

Os verbetes foram elaborados de acordo com uma estratégia que distingue três grandes tipos: os verbetes âncora, referenciados a entradas consideradas estruturais para a abordagem conceptual proposta na obra (conceitos, processos, periodizações, instituições, géneros, estilos, personalidades, obras musicais); os verbetes associados a entradas relativas a tipologias de agrupamentos, instituições, eventos, géneros, estilos e instrumentos que dão consistência aos diferentes circuitos musicais; e os verbetes de caráter mais específico, associados a entradas sobre indivíduos, instituições, instrumentos, publicações.

O resultado é uma volumosa obra, que compila e disponibiliza um vasto conjunto de informação acerca de variadíssimos aspetos dos universos musicais que marcaram o século Xx português. Por essa razão se torna muito difícil distinguir ou evidenciar o conteúdo de entradas específicas.

Ainda assim, gostaria de destacar, por razões que se prendem com a relevância da informação contida, um dos verbetes âncora. Aquele que se refere a "Arquivos, Bibliotecas e Museus". O destaque relaciona-se com o facto de o inventário de arquivos, bibliotecas e museus apresentado ser um importante guião para investigadores, profissionais e interessados que se debatem com a dificuldade de identificação das potenciais instituições que acolhem e conservam informação relativa a música escrita, gravada, profana ou religiosa. A longa lista de instituições referenciadas testemunha a flagrante e prolongada ausência de políticas públicas de caráter estratégico, orientadas para o domínio do património musical nacional, ao contrário do que acontece, por exemplo, no que diz respeito ao património nacional do livro. A ausência de legislação definidora do depósito obrigatório de obras musicais escritas ou gravadas e, complementarmente, de um arquivo central neste domínio, constituem sérios obstáculos não apenas à investigação e ao conhecimento da esfera musical nacional, 
mas também à preservação do património e da memória de um domínio cultural particularmente dinâmico e volátil.

A EMPXX constitui um esforço da comunidade científica nacional, e em particular da equipa do INET-MD, liderada por Salwa Castelo-Branco, para minimizar estas dificuldades, oferecendo um guia de navegação que tanto incorpora referências a elementos dos domínios mais estudados e sistematizados da esfera musical, como o da música erudita, ou mesmo do fado ou da música tradicional, como menções a elementos de domínios mais específicos e pouco conhecidos do pop-rock, do punk ou do hip-hop.

Paula Abreu 
